\title{
Proof Without Words: From Floor to Stairs
}

\section{JULIJE JAKŠEtić $\odot$} 1/ 7 e present a geometric interpretation of the

$$
\sum_{k=1}^{\infty}\left\lfloor\frac{r}{k}\right\rfloor^{2}=\sum_{k=1}^{\infty}(2 k-1)\left\lfloor\frac{r}{k}\right\rfloor
$$

Julije Jakšetić

Faculty of Food Technology and Biotechnology,

Section for Mathematics

Pierottijeva 610000 Zagreb

Croatia

e-mail: jjaksetic@pbf.hr
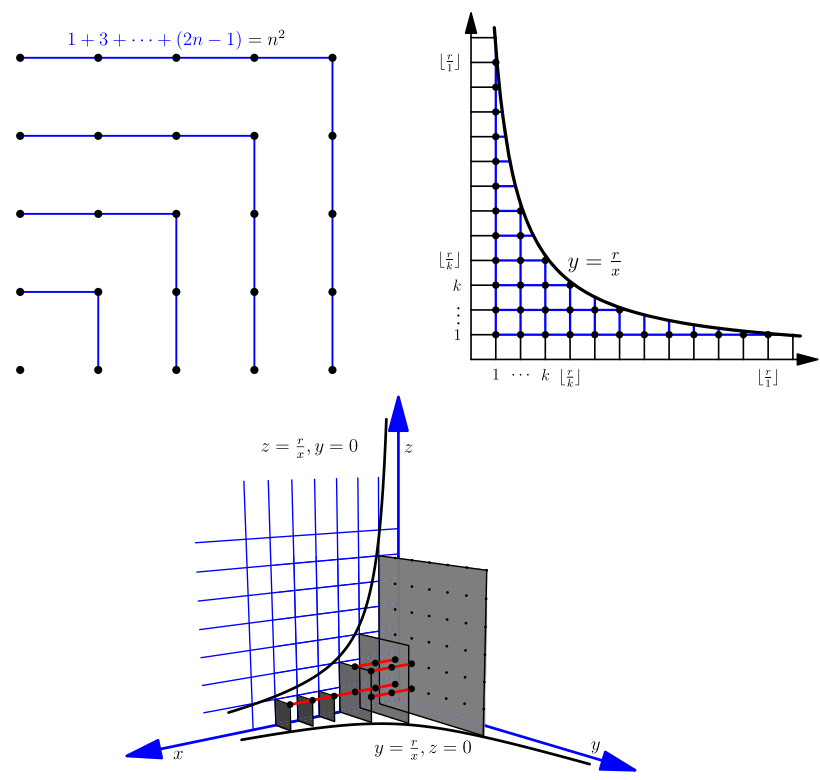

$\sum_{k=1}^{\infty}\left\lfloor\frac{r}{k}\right\rfloor^{2}=\sum_{k=1}^{\infty}(2 k-1)\left\lfloor\frac{r}{k}\right\rfloor$

${ }^{1}$ This identity can be found in many books on elementary number theory. The earliest mention appears to be in M. A. Heaslett and J. V. Uspensky, Elementary Number Theory, McGraw-Hill, 1939 (Problem 10, p. 98). 